\title{
FORMULATION OF THE MEMBERSHIP FUNCTION AND DETERMINATION OF THE INPUT OF FUZZY LOADS IN THE STRUCTURAL FUZZY ANALYZING PROBLEM
}

\author{
NGUyen Van Pho \\ Hanoi University of Civil Engineering
}

\begin{abstract}
The fuzzy analyzing process consists of different steps. In this paper, the author considers only the method for formulation of the membership function of fuzzy loads acting on the structure. Based on the membership function of fuzzy loads, the combinations of deterministic of the regression analyzing process will be determined. The membership function of fuzzy loads is selected by the triangular membership function. It is in conformity with the concept on selection of loads in the design standards. The combination of inputs for the analyzing process will be determined, based on the number of present times of the value of input parameters (including the deterministic parameters, fuzzy parameters and the random ones) in the schema of analysis.

The number of present times of input parameters is either proportional to value of the corresponding membership function or to the value of the probabilistic density function. A method for determining the appropriate combination of deterministic inputs so that each input parameter will present only one time in each combination is proposed.

To illustrate the proposed method, an example on the determination of input combinations of tornado's velocity in Vietnam is presented.
\end{abstract}

\section{INTRODUCTION}

In the structural fuzzy analyzing problem, the deterministic parameters, fuzzy parameters and the random ones are often simultaneously present. More details about the uncertainty parameters taken into account in structural analysis are presented in the references $[1,2,3,4, .$.$] .$

Structural fuzzy analysis is done according to the following schema [4]

- The input of the analyzing process is composed of physical, geometrical and load's parameters. These parameters may be the deterministic parameters, random parameters or the fuzzy ones.

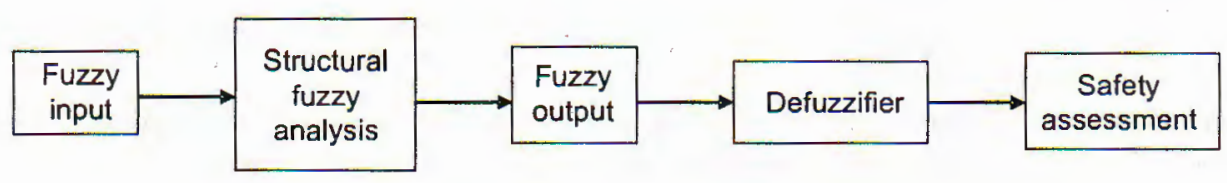

Fig. 1. Schema of fuzzy analysis of structure 
- Structural fuzzy analysis is the structural calculation process with the participation of fuzzy parameters.

- Structural fuzzy analysis can be carried out according to different methods $[1,2,3$, $4,5,6]$.

- Fuzzy output is the result of a fuzzy analysis process. In general, the fuzzy output is the response of structures.

- Defuzzifier is to convert the fuzzy output to the deterministic values. To do the defuzzifier, we may use one of the following methods: method of centre of gravity, weight average method, maximum membership function method, and so on.. [1, 7, 8..].

- In the fuzzy reliability analysis problem, the output is the reliability and it is a deterministic number in the range of $[0,1]$. This means, the output has been defuzzifiered $[2,5,6, .$.$] .$

- The safety assessment is the determination of safety degree (reliability) of the structure on the basis of design code. From the above analysis, we can see that the first work to do is to determine the input for the analyzing process. The commonly algorithms used to analyze the structure require that the input must be deterministic data sets. Therefore, to calculate, we have to convert the fuzzy input to the deterministic data sets. This conversion is very important because it directly influences on the analyzing results.

It is regretful that up to now, the determination of deterministic input for fuzzy analyzing process has juts considered sparsely in very few literatures $[1,2 \ldots]$.

As we know, to present a fuzzy parameter, we often use its membership function. However, based on this membership function, the input of the fuzzy analyzing process cannot be directly determined.

Therefore, in this paper, the author recommends a method to formulate the membership function of fuzzy loads and from this membership function, the deterministic input of the fuzzy analyzing process will be determined.

To coincide with the properties of the loads in structural analyzing as well as to make it convenient for the application, in this paper, the author deals with the triangular membership function only.

To illustrate the proposed method, an example on the determination of input combinations of tornado's velocity in Vietnam is presented.

\section{FORMULATION OF THE MEMBERSHIP FUNCTION OF FUZZY LOADS}

\subsection{Loads in structural analysis}

The load parameter plays an important role in structural analysis. The loads are specified in design standards.

In fact, there is a difference between the actual loads and that specified in design standards. Therefore, adjusting coefficients are often used in order to increase or decrease some quantities during analyzing and calculating. Determination of the adjusting coefficients is generally based on either the actual experience or the safety probability (the reliability) of the structure. In cases of data shortage (new types of structures, new materials and unusual weather), the data required is not enough for calculating the reliability and as a result, the above coefficients cannot be exactly determined. 
Essentially, loads that act on the structures (typhoons, earthquakes, sea waves,..) are either the random variables or the fuzzy ones. Generally, these are the random or the fuzzy field $[1,6]$. But, when analyzing a structure, it is recognized that load is a deterministic value and this value (in fact) is different from it true value and the error may be either the random or the fuzzy variable.

Nowadays, with the presence of new types of structure and materials, in addition to the unusual natural disasters, the fuzzy nature (uncertainty) of the load is an evident truth $[1,9,10]$.

In the deterministic calculating situation (where the above error is considered as zero), to compensate for the error, people often use the corrected coefficients in the design standards.

In the random calculating situation, the error is considered as the random variable. The random value is taken into account in the calculation schema for determining the reliability of structure $[6,9,11]$.

In the fuzzy regression calculating situation, the deterministic value used for calculating is the believable value of the fuzzy variable and this value corresponds to the membership function $\mu(\mathrm{x})=1$. Error of the load around the believable value is proportional to the corresponding membership function. Thus, with a fuzzy input parameter, there are many different values taken into account in the regression analyzing process.

To formulate the membership function of a fuzzy variable, one of the following methods are often used: visual method, deducing method or professional method $[1,7,8]$.

The appropriate method shall be selected depending on the property, the quantity of information obtained and the requirement of the application. In this paper, the author selects the deducing method for formulating the membership function of loads.

\subsection{Formulation the membership function of fuzzy loads}

To establish the membership function of fuzzy loads, we should carry out the following steps:

- Step 1: Estimate the upper and lower bounds of the load, namely, it is supposed that the load be in a range. However, the distribution rule in this range is not clear (it is fuzzy).

The determination of the upper and lower bounds shall be carried out based on the obtained information about the load and, based on the structural safety requirement.

If the above bounds of the load cannot be estimated, we should divide the load range into many smaller ones and then, the calculation shall be done with each divided small range. Then, summarize all the obtained results to make the final assessment on the safety of the structure.

- Step 2: Select discrete values of the load in the variable range, each discrete value of load shall have a corresponding triangular membership function.

- Step 3: Formulate the triangular membership function.

Each load value (here, it is a discrete point) selected as the load for calculating is corresponding to the believable value of the fuzzy parameter $(\mu(x)=1)$, which corresponds to a vertex of the triangular of the membership function. The other vertices of the triangular are the two bounds of the load (see F,ig. 2).

At the two bounds $A$ and $B$, the membership function is a square triangular. 


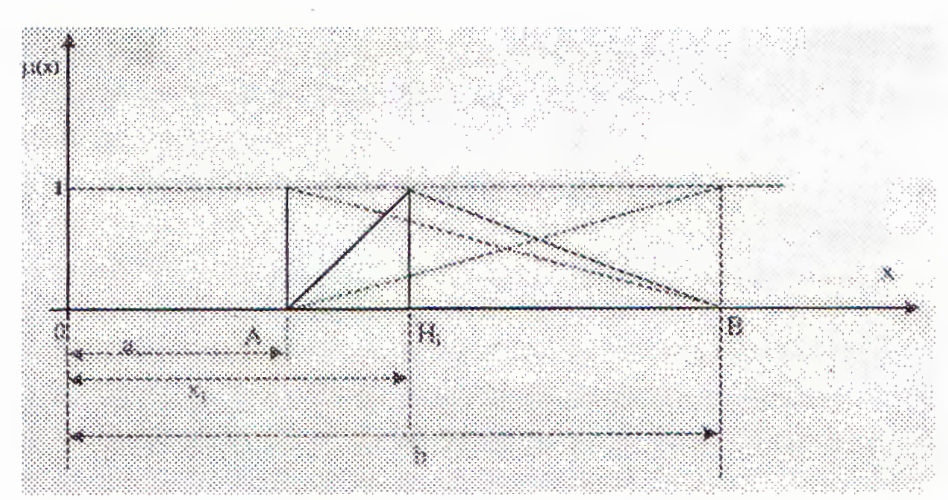

Fig. 2. The triangular membership function at $x_{i}$ follows:

The expression of the membership function $\mu(x)$ (at the point with $\mu_{i}\left(x_{i}\right)=1$ ) is as

$$
\mu_{i}(x)=\left\{\begin{array}{l}
0 \text { if } x=a \\
\frac{x}{x_{i}-a}+\frac{a}{a-x_{i}} \\
0 \text { if } x>b
\end{array} \text { if } a \leq x \leq x_{i}\right.
$$

At the lower bound $A$, the expression of the membership function will be:

$$
\mu_{A}(x)=\left\{\begin{array}{l}
0 \text { if } x>a \\
\frac{x}{a-b}+\frac{b}{b-a} \text { if } a \leq x \leq b \\
0 \text { if } x>b
\end{array}\right.
$$

At the upper bound $B$, the expression of the membership function will be:

$$
\mu_{B}(x)=\left\{\begin{array}{l}
0 \text { if } x>a \\
\frac{x}{b-a}+\frac{a}{a-b} \\
0 \text { if } x>b
\end{array} \quad \text { if } a \leq x \leq b\right.
$$

\section{DETERMINATION OF THE DETERMINISTIC FOR THE CALCULATING PROCESS}

The relationship between the fuzzy set theory and the probabilistic theory has been mentioned in some literatures $[1,3,12$.$] .$

As far as we know, the value of probabilistic density function, $f(x)$, of the random variable corresponds to the appeared frequency of the value of $x$ during the observing process $[13,14, .$.

With a fuzzy value, the membership function, $\mu(x)$ shows the membership level of $x$ of the fuzzy parameter to the believable value (the value with which, the membership function is equal to 1 ).

Mathematically, the uncertainty of the fuzzy value can not satisfy all the strict requirements of the random variable. We can say that random variable is a specific case of fuzzy variable. Therefore, the meaning of membership function and the density function is not totally identical. However, with respect to the number of present times in the regression 
calculation, we can regard that the probabilistic density function and the membership function are similar to each other.

From the above remarks, the determination of input of fuzzy parameters for the structural analyzing process should consist of the folløwing steps:

Step 1: Formulate the triangular membership functions (see the item 2 above).

Step 2: Select discrete values of the variable range of fuzzy loads.

Step 3: Determine the number of present times in the calculation schema of the discrete values $x_{i}$ of the fuzzy parameter according to the formula:

$$
N_{i}=\text { whole part of }\left[\mu\left(x_{i}\right) \cdot n\right],
$$

Where $N_{i}$ is the number of present times of values of $x_{i}, \mu\left(x_{i}\right)$ is the membership function, $n$ is the number of present times in the calculation schema of the believable value of $x_{j}$ with $\mu\left(x_{j}\right)=1$. The value of $\mathrm{n}$ shall be appropriately selected so that all the discrete values can participate in the calculating process and in addition, $n$ should be in conformity with the calculation ability.

With regard to the random value, we can do in the same way. However, the membership function $\mu(x)$ is replaced with density function $f(x)$ and $n$ is the number of present times of value of $x_{I}$ with:

$$
F\left(x_{I}\right)=\max _{\{i\}} f\left(x_{i}\right)
$$

The variable range of the random variable shall be determined in such a way that it. covers a probability that is big enough, satisfying the accurate requirement expected by the problem.

Due to the different presence frequencies or the different believable levels, the discrete values of the load in the variable range will present in the regression calculating process with different number of times.

The deterministic value presents one time and the number of present times of the random and fuzzy quantities depends on the formula (3.1).

If the number of present times of the input parameters (including deterministic, random and fuzzy parameters) is $N$, and $k$ is the number of input parameters, then the combinations of $k$ from $N$ values is:

$$
C_{N}^{k}=\frac{N !}{k !(N-k) !}
$$

It contains the combinations that have more than one value of each input parameter and these combinations should be eliminated because in each combination taken into account in regression analysis, each input parameter is allowed to present one time only.

Listing the possible combinations and eliminating the inpossible combinations is a simple problem. The possible input combinations can be determined with the graph method (please see the item 4 hereinafter).

When the listing of possible input combinations is completed, the combinations are taken into account. If the calculating quantity is too large and the calculation ability'is so limited that the analyzing operation can not be implemented, we can reduce the above calculating quantity according to the following method: 


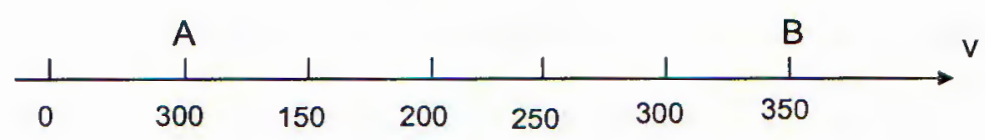

Fig. 3. Discrete value of tornado's velocity

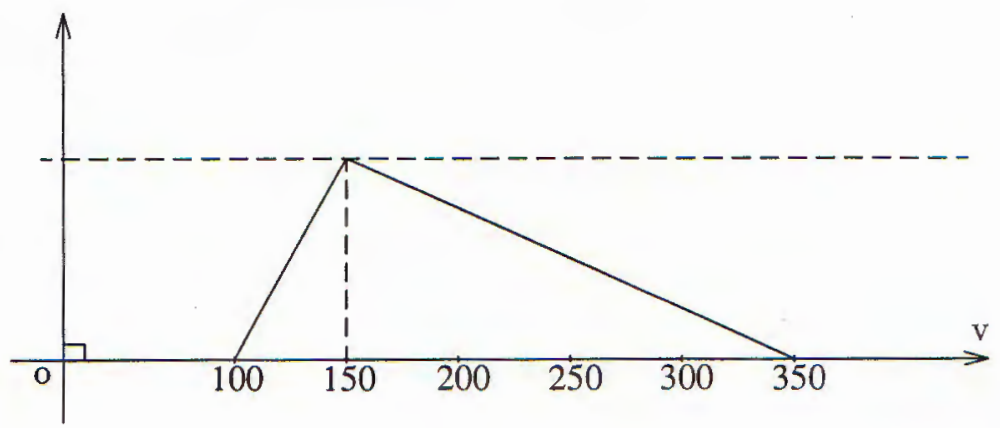

Fig. 4. Membership function of tornado's velocity with the believable value of $150 \mathrm{~km} / \mathrm{h}$

Regard the input combinations selected in the step 3 as the equivalent combinations, because the number of present times was adjusted from the density and membership functions. The number the combinations is selected randomly according to Monte-Carlo method for reducing the possible combinations[19].

\section{EXAMPLE: TORNADO LOADS IN VIETNAM}

\subsection{Estimation of the bounds}

Due to the shortage of monitoring instruments and due to the long-lasting war in Vietnam, many meteorological stations stopped working for many years. In addition, for many years, many meteorological stations have not paid attention to tornados so the tornados' data base in Vietnam is very poor and it is not enough for statistical treatment $[15,16,17,18]$. However according to the monitored data, tornados often take place in Vietnam with a velocity varying in the range of $100 \mathrm{~km} / \mathrm{h}$ to $170 \mathrm{~km} / \mathrm{h}$. Sometimes, tornados have taken place with the estimated velocity varying in the range of $300 \mathrm{~km} / \mathrm{h}$ to $320 \mathrm{~km} / \mathrm{h}$. Therefore, we can expect that the variable range of the tornado's velocity in Vietnam is from $100 \mathrm{~km} / \mathrm{h}$ to $350 \mathrm{~km} / \mathrm{h}$. Due to the data shortage, we can say that the distribution rule of the tornado's velocity in the variable range is fuzzy.

\subsection{Select discrete values of the tornador's velocity}

Divide the variable range of tornado's velocity into 5 smaller ones (see Fig. 3)

\subsection{Formulation of the membership function}

$$
\mu_{100}(v)=\left\{\begin{array}{l}
0 \quad \text { if } v=0 \\
-\frac{x}{250}+\frac{7}{5} \\
0 \text { if } v>350
\end{array} \quad \text { if } 100 \leq v \leq 350\right.
$$




$$
\begin{aligned}
& \mu_{150}(v)=\left\{\begin{array}{l}
0 \text { if } v=100 \\
\frac{x}{50}-2 \quad \text { if } \quad 100<v \leq 150 \\
-\frac{x}{200}+\frac{7}{5} \quad \text { if } \quad 150 \leq v \leq 350 \\
0 \text { if } x>350
\end{array}\right. \\
& \mu_{350}(v)=\left\{\begin{array}{l}
0 \text { if } v<100 \\
\frac{x}{50}-\frac{2}{5} \quad \text { if } 100 \leq v \leq 350 \\
0 \text { if } v<350
\end{array}\right.
\end{aligned}
$$

With other value of $x_{i}$, we have the same expressions.

\subsection{Determining the number of present times in the regression calculating schema of the discrete values of tornado's velocity}

According to the formula (3.1), hereinafter we determine the number of present times of the discrete values in the calculating process with the tornado's believable velocity of $150 \mathrm{~km} / \mathrm{h}$.

To let the velocity $v=350 \mathrm{~km} / \mathrm{h}$ present one time, we choose $n$ as $5(n=5)$.

$v=100 \mathrm{~km} / \mathrm{h}$ presents one time is numbered as $x_{1}$;

$v=150 \mathrm{~km} / \mathrm{h}$ presents five times are numbered as $x_{2}, x_{3}, x_{4}, x_{5}, x_{6}$;

$v=200 \mathrm{~km} / \mathrm{h}$ presents four times are numbered as $x_{7}, x_{8}, x_{9}, x_{10}$;

$v=250 \mathrm{~km} / \mathrm{h}$ presents three times are numbered as $x_{11}, x_{12}, x_{13}$;

$v=300 \mathrm{~km} / \mathrm{h}$ presents two times are numbered as $x_{14}, x_{15}$;

$v=350 \mathrm{~km} / \mathrm{h}$ presents one times are numbered as $x_{16}$;

Therefore, there will be 16 values of tornado's velocity to be taken into account.

\subsection{Determining deterministic input for the analyzing process}

Generally, in the structural analyzing problem, there is a simultaneous participation of three types of parameters: deterministic, random and fuzzy. The random and fuzzy parameters may receive many values, namely, they present many times.

However, in each input combination each input parameter is allowed to present one time only.

Supposed that there is a deterministic parameter whose sign is $x_{17}$ and, a random parameter that may receive 4 values whose signs are $x_{18}, x_{19}, x_{20}, x_{21}$.

Finally, with three input parameters, they may receive 21 values. The combination of 3 from 21 is $C_{21}^{3}$ :

$$
C_{21}^{3}=\frac{21 !}{3 !(21-3) !}=1330 \text {. }
$$

The combinations that contain 2 or 3 fuzzy values or that contain 2 or 3 random values should be eliminated. The final number of combinations is only 64 , this means that the number of combinations was considerably reduced! This result can be checked according to the following figure:

The values are recorded in three columns: deterministic, fuzzy and random.

It is obvious that: $x_{1}=x_{2}=x_{3}=\ldots=x_{16}$ and $x_{18}=x_{19}=x_{20}=x_{21}$. 


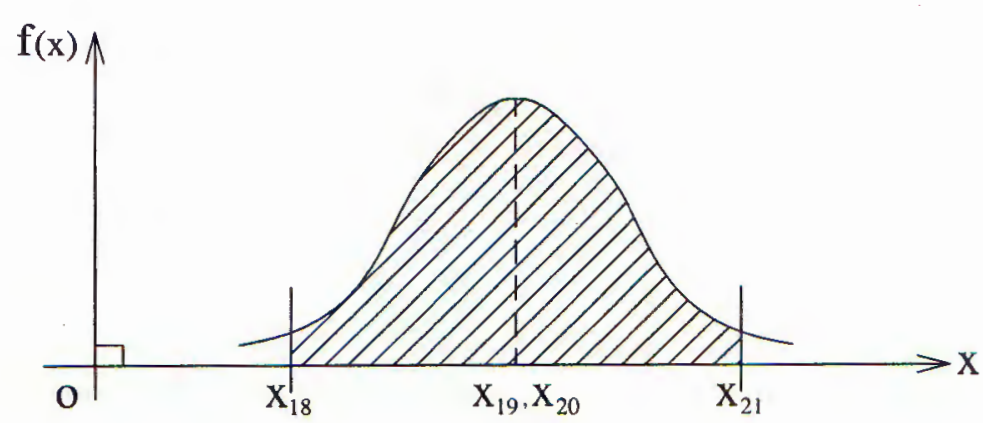

Fig. 5. Discrete values of the random parameter

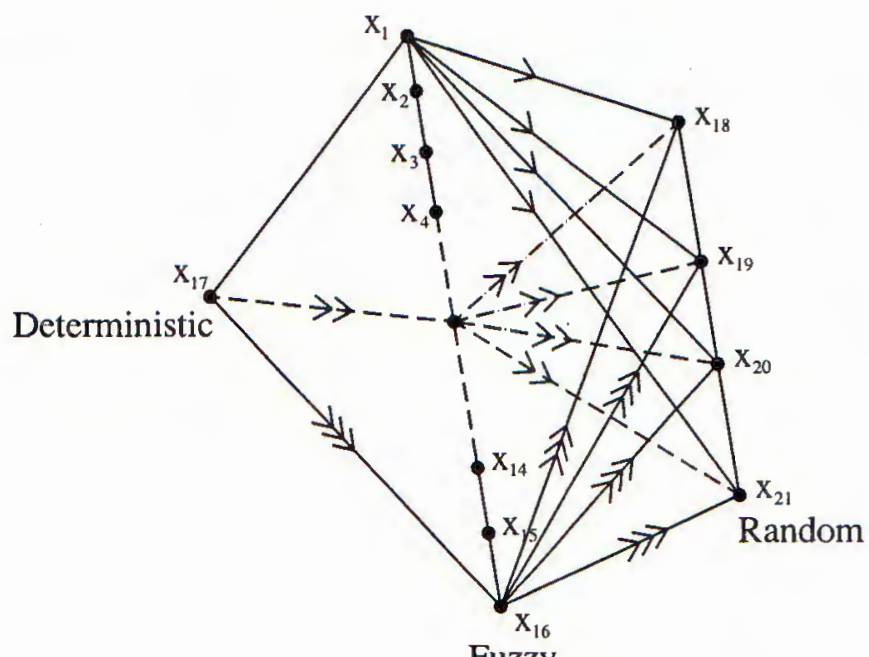

Fuzzy

Fig. 6. Combination of the input values

Value of $x_{17}$, when combined with a fuzzy value and random values (4 values), results in 4 combinations. Because there are 16 fuzzy values, the number of combinations will be: $4 \times 16=64$ (combinations).

We can list the deterministic value combinations as follows:

$$
\begin{aligned}
& \left(x_{17}, x_{1}, x_{18}\right),\left(x_{17}, x_{1}, x_{19}\right),\left(x_{17}, x_{1}, x_{20}\right),\left(x_{17}, x_{1}, x_{21}\right) \\
& \left(x_{17}, x_{14}, x_{18}\right),\left(x_{17}, x_{14}, x_{19}\right),\left(x_{17}, x_{14}, x_{20}\right),\left(x_{17}, x_{14}, x_{21}\right) \\
& \left(x_{17}, x_{16}, x_{18}\right),\left(x_{17}, x_{16}, x_{19}\right),\left(x_{17}, x_{16}, x_{29}\right),\left(x_{17}, x_{16}, x_{21}\right)
\end{aligned}
$$

\section{CONCLUSION}

- This paper has presented the way to determine fuzzy loads and the deterministic input of the structural analyzing process. This paper did not deal with analyzing methods and the treatment of analyzed results; 
- In the fuzzy regression analysis, the determination of central value of the fuzzy output is carried out with the normal regression operation. The tolerance of fuzzy output is determined by applying the extended Zadeh principle (to solve an extreme problem) $[5$, $6,7]$.

- The extension of the results presented in this paper for the input that contains many deterministic, random and fuzzy variables is not difficult, however, as a matter of course, the calculating quantity will be increased. Nowadays this problem can be overcome owing to the computer;

- To formulate the membership function for fuzzy variables in structural analysis, we can use different membership functions and different methods. In this paper, the author has used the triangular membership function based on the concept on loads in structural design.

- The assessment of error of the fuzzy analyzing process due to the approximate input selection is a question that has not been studied yet. If it is required to increase the accuracy, the number of discrete points must be increased and of course, the calculating quantity also increases.

Acknowledgement. This paper is completed with the financial support from the Basic research programme in Natural science fields. The Author would like to thank to Ministry of Science and Technology of Vietnam and Natural Scientific Council for the financial support.

\section{REFERENCES}

1. Bernd Möller and Michael Beer, Fuzzy Randomness-Uncertainty in Civil Engineering and Computational Mechanics, Springer, 2004.

2. Nguyen Van Pho, Nguyen Dinh Xan and Nguyen Thac Vu, A method for calculation of reliability of buildings with the participation of fuzzy variables. Journal of Building Science and Technology 3 (2005) (in Vietnamese).

3. H. J. Zimmermann, Fuzzy Sets and its Application, $2^{\text {nd }}$ Ed. Kluwer Acad. Pub. 1991.

4. Nguyen Van Pho, Le Ngoc Thach and Tran Van Lien, The technical diagnosing problem in the fuzzy information condition, Proceedings of the $8^{\text {th }}$ National Scientific Conference on Solid Mechanics, Thai Nguyen, 6/2006. pp. 619-627 (in Vietnamese).

5. K. K. Yen, S. Ghohray and G. Roig, A linear regression model using triangular fuzzy number coefficients, Fuzzy sets and Systems 106 (1999) 167-177.

6. Li Bing, Zhu Meilin and Xu Kai, A practical engineering method for fuzzy reliability analysis of mechanical structures, Reliability engineering and System Safety 67 (2000) 311-315.

7. Bui Cong Cuong (chief editor), Fuzzy Systems, Neuron Net and Application, Scientific and Technical Pub. House, Hanoi, 2001 (in Vietnamese).

8. Nguyen Nhu Phong, Fuzzy Sets Theory and it's Application, Scientific and Technical publishing House, Hanoi, 2005 (in Vietnamese).

9. Nguyen Van Pho, The safety of building structures subject to unusual natural and man-made disasters in the $21^{\text {st }}$ century, Proceeding of the $15^{\text {th }}$ Scientific - Technological Conference, Hanoi University of Civil Engineering, Hanoi, 2006. pp.18-25 (in Vietnamese).

10. Nguyen Van Pho, Application of the theory "Selection of decision in the uncertainty cases" to the evaluation of occurrences of buildings due to natural disasters, Proceedings of the $2^{\text {nd }}$ National Scientific Conference on Occurrence and Damage to Building structures, Hanoi, 12/2003. pp. 299-310 (in Vietnamese).

11. International Standard ISO 2394-1998, General principles on Reliability of Structures 
12. Dinh Manh Tuong, Artificial Intelligence, Scientific and Technical publishing House, Hanoi, 2002 (in Vietnamese).

13. Achintya Haldar, Probability, Reliability and Statistical Methods in Engineering Design, John Wiley and Sons, 2000.

14. V. V. Bolotin, Statistical Methods in Structural Mechanics, Moscow, 1965 (in Russian).

15. Nguyen Van Pho, Typhoons, Tornados and Protection of Buildings against Typhoon and Tornados, Construction publishing House, Hanoi, 1991 (in Vietnamese).

16. Nguyen Van Pho et al, Action of tornados on buildings and protection of buildings subjected to tornado, Ministry-level research theme, Ministry of Construction, Code RD 19-01-2002 (in Vietnamese).

17. Nguyen Van Pho, Le Dinh Quang, Pham Van Tu, Tornados in Vietnam and its influence on buildings, Proceedings of the Structural and Construction Technological Conference 2000, Hanoi, 12/2000, pp.82-89 (in Vietnamese).

18. Mai Trong Thong and Hoang Luu Thu Thuy, Distribution of storms and tornados in Vietnam territory, Journal of the Earth sciences 26 (2004) 043-49 (in Vietnamese).

19. Andrzej S. Nowak, Kevin R. Colins, Reliability of Structures, Mc Graw Hill. Inter. Edition, 2000 .

Received April 27, 2007

\section{XÂY DỰNG HÀM THUỘC VÀ XÁC ĐịnH ĐẦU VÀO CỬ TẢI TRỌNG MỜ TRONG BÀI TOÁN PHẦN TÍCH MỜ KỂT CẤU}

Quá trình phân tích mờ kết cấu gồm nhiều bước khác nhau. Trong bài này tác giá chỉ xét phương pháp xây dựng hàm thuộc của tải trọng mờ tác dụng lên công trình. Từ hàm thuộc của tải trọng, xác định các tổ hợp đầu vào tất định của quá trình phân tích hồi quy có các biến ngẫu nhiên và biến mờ tham gia.

Hàm thuộc của tải trọng mờ được chọn là hàm thuộc tam giác, vì nó phù hợp với quan niệm về chọn tải trọng trong các tiêu chuẩn thiết kế.

Xác định các tổ hợp đầu vào cho quá trình phân tích, dựa theo số lần xuất hiện của các giá trị của các tham số đầu vào (tất định, mờ và ngẫu nhiên) trong sơ đồ tính toán.

Số lần xuất hiện cưa tham số đầu vào tý lệ với giá trị hàm thuộc hay hàm mật độ xác suất tương ứng. Đã đề xuất phương pháp tìm tổ hợp đầu vào tất định thích hợp, sao cho mỗi tham số đầu vào chi được xuất hiện một lần trong mồi tổ hợp.

Để minh hoạ cho phương pháp nêu ra, một thí dụ về tìm các tổ hợp đầu vào của vận tốc gió lốc \&̛ Việt Nam đã được xét. 